\title{
A Low Pass Filter With sub-Hz Cutoff Frequencies for a Portable On-Chip Lock-in Microinstrument
}

\author{
Jorge Pérez-Bailón, Belén Calvo, Nicolás Medrano \\ Grupo de Diseño Electrónico (GDE) \\ Instituto de Investigación en Ingeniería de Aragón (I3A) \\ Universidad de Zaragoza, Mariano Esquillor s/n, 50018, Zaragoza, Spain. \\ Tel. +34-876553257, e-mail: jorgepb@unizar.es
}

\begin{abstract}
This paper presents a first-order single-ended fullyintegrated Low Pass Filter (LPF) tunable from $114 \mathrm{mHz}$ to $2.5 \mathrm{kHz}$, designed to conform the output stage of a portable lock-in amplifier requiring $\mathrm{f}_{\mathrm{c}}=0.5 \mathrm{~Hz}, 5 \mathrm{~Hz}$ cutoff frequencies. It achieves the two target $\mathrm{f}_{\mathrm{c}}$ over a -40 to $120^{\circ} \mathrm{C}$ range with a power consumption of $2.7 \mu \mathrm{W}$ at $1.8 \mathrm{~V}$ supply, compact size and dynamic range above $80 \mathrm{~dB}$.
\end{abstract}

\section{Motivation}

LPFs with very low cutoff frequencies $\left(f_{c}\right)$ are key blocks in front-end sensor interfaces, where they serve as pre-conditioning stages to reduce noise and increase resolution over the frequencies of interest, such as in biomedical systems [1], or as DC extractors, placed in the last stage of the readout chain and requiring sub- $\mathrm{Hz} \mathrm{f}_{\mathrm{c}}$, such as in lock-in amplifiers (LIA). The latter is the motivation of this study: the design of a LPF constituting the final stage of a CMOS dual-phase LIA (Fig. 1) to be used in a portable on-chip instrument. Most integrated LIAs use off chip resistors and capacitors, keeping the LPF external, because the integration of low $f_{c}$ filters with low noise and wide linear input range is not trivial, being a real challenge if compact size and low power must be also satisfied.

\section{Proposed LPF}

A $G_{m}-C$ approach (Fig. 2) is adopted to attain a high impedance input node, which makes straightforward the coupling between stages. The core is a mirrored cascode OTA. The input NMOS differential pair remains unaltered, so that the bias point is not moved from its optimum value. The $\mathrm{G}_{\mathrm{m}}$ reduction and tuning is done in the output stage, exploiting a cascode current mirror steering technique: the cascode gate voltage $\mathrm{V}_{\mathrm{C}}$ is replaced by complementary control voltages $\mathrm{V}_{ \pm}=\mathrm{V}_{\mathrm{C}} \pm \mathrm{V}_{\mathrm{gc}}$ [2], as shown in Fig. 3, so that output current is split into currents $\mathrm{I}_{\mathrm{A}}$ and $\mathrm{I}_{\mathrm{B}}$, each with complimentary gain $\left\{\mathrm{K}_{\mathrm{i}},\left(1-\mathrm{K}_{\mathrm{i}}\right), 0<\mathrm{K}_{\mathrm{i}}<1\right\}$, adjustable depending on the value of $\mathrm{V}_{\mathrm{gc}}$. Output $\mathrm{B}$ is the integrator output, and output $\mathrm{A}$ is kept at $\mathrm{V}_{\mathrm{dd}} / 2$ to preserve symmetry and assure linear current division.

The LPF has been designed in the $0.18 \mu \mathrm{m}$ CMOS technology from UMC, with $\mathrm{V}_{\mathrm{dd}}=1.8 \mathrm{~V}$ and $\mathrm{V}_{\mathrm{cm}}=0.9 \mathrm{~V}$. The capacitor has been set to $50 \mathrm{pF}$, considered the maximum practical on-chip value. The bias current IBias is set to $500 \mathrm{nA}$. The tuning voltage $\mathrm{V}_{\mathrm{gc}}$ can be varied in a range from 0 to $\sim 200 \mathrm{mV}$, ensuring a DC gain error below $0.5 \mathrm{~dB}$ and a maximum offset of $\pm 1 \%$ over a temperature range from -40 to $120^{\circ} \mathrm{C}$. Fig. 4 shows the filter magnitude response at room temperature by steeping $V_{g c}$ : the $f_{c}$ can be linearly tuned from $2.5 \mathrm{kHz}$ to $114 \mathrm{mHz}$. For $\mathrm{f}_{\mathrm{c}}=0.5,5 \mathrm{~Hz}$ input linear range is $0.13-1.51 \mathrm{~V}, \mathrm{THD}=1 \% @ 0.72 \mathrm{mV}_{\mathrm{pp}}$ (Fig. 5) and noise $12.8 \mu \mathrm{V}_{\text {rms }}$, which renders a dynamic range of over $80 \mathrm{~dB}$. The $f_{c}$ variations over corners and temperature can be adjusted to the target values thanks to the proposed scheme. The main performances are summarized in Table 1 and compared with previous designs with similar specifications $[1,3,4]$.

\section{Conclusions}

A very low frequency LPF topology has been presented, showing very competitive performances in terms of achievable cut-off frequencies, dynamic range, power consumption and reduced area thanks to the use of a very simple $G_{m}$ reduction-tuning technique based on current steering current mirrors.

\section{REFERENCES}

[1]. R. RIEGER et al. A 230-nW 10-s Time Constant CMOS Integrator for an Adaptive Nerve Signal Amplifier, IEEE J. Solid-State Circuits, vol. 39, no. 11, pp. 1968-1975, Nov. 2004.

[2]. J. RAMIREZ-ANGULO et al. New Gain Programmable Current Mirrors Based on Current Steering, IEEE MWSCAS, 2006.

[3]. P. BRUSCHI et al. A Fully Integrated Single-Ended 1.515-Hz Low-Pass Filter With Linear Tuning Law, IEEE J. Solid-State Circuits, vol. 42, no. 7, pp. 1522-1528, Jul. 2007.

[4].E. RODRIGUEZ-VILLEGAS et al. A sub-Hertz nanopower low pass filter, IEEE Trans. Circuits and Systems II: Exp. Briefs, vol. 58, pp. 351-355, 2011. 


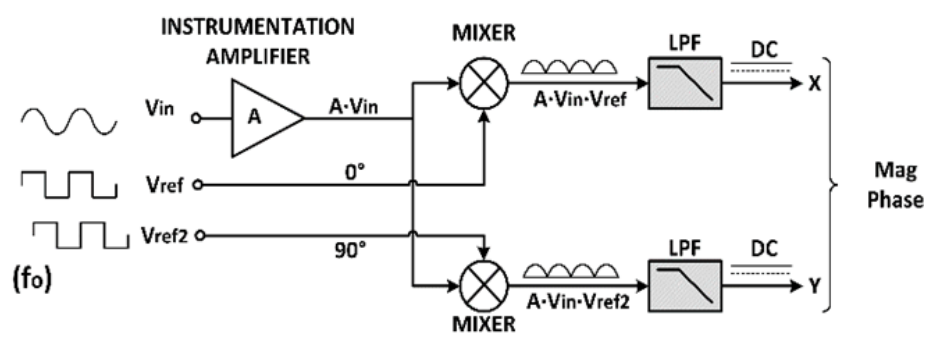

Figure 1: Block diagram of a Dual-Phase Lock-In Amplifier.

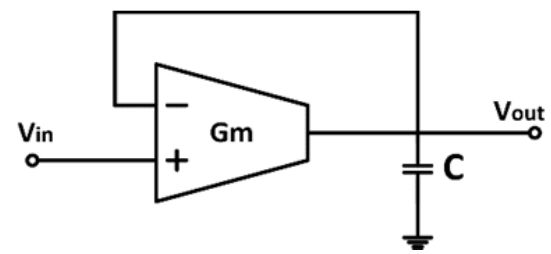

Figure 2: Single-ended basic $G_{m}-C$ integrator.

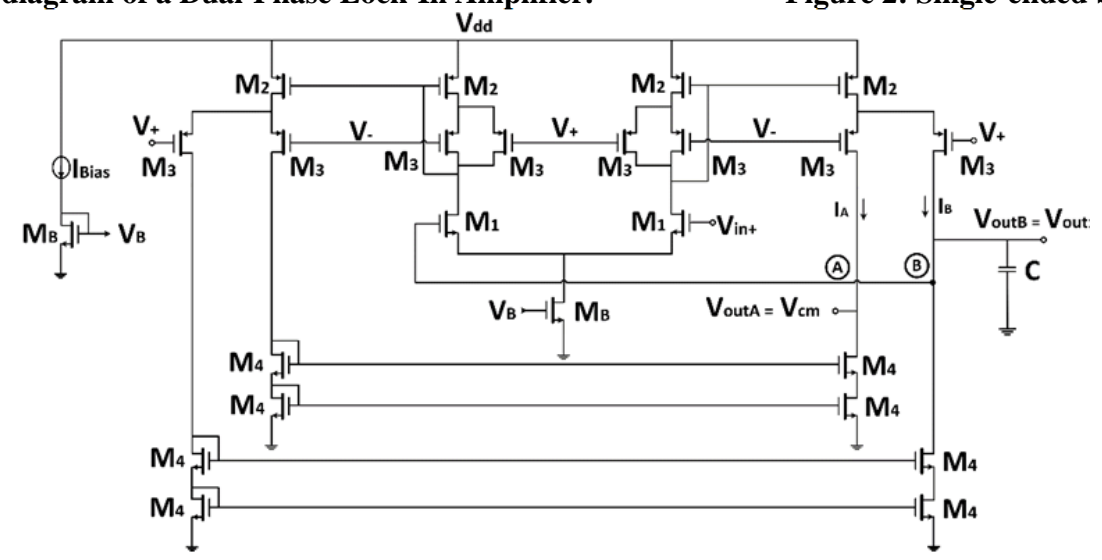

Figure 3: Proposed LPF based on current steering mirrored cascode OTA.

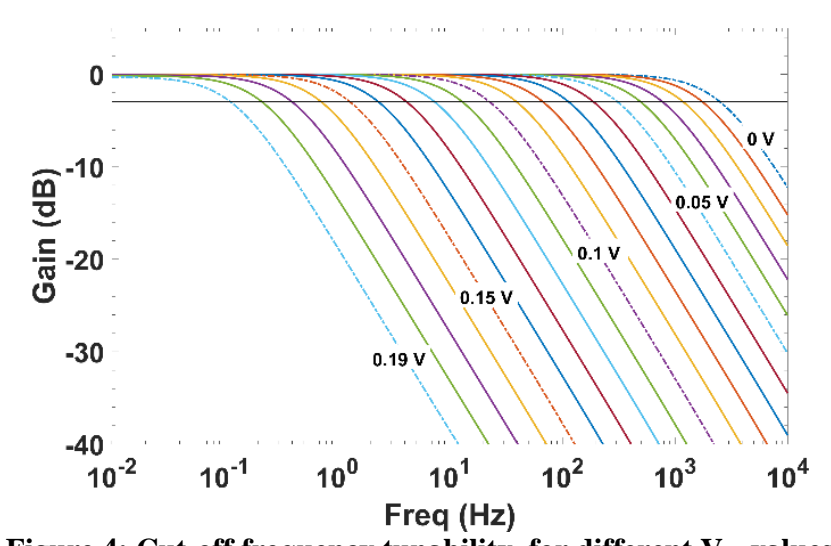

Figure 4: Cut-off frequency tunability, for different $\mathrm{V}_{\mathrm{gc}}$ values.

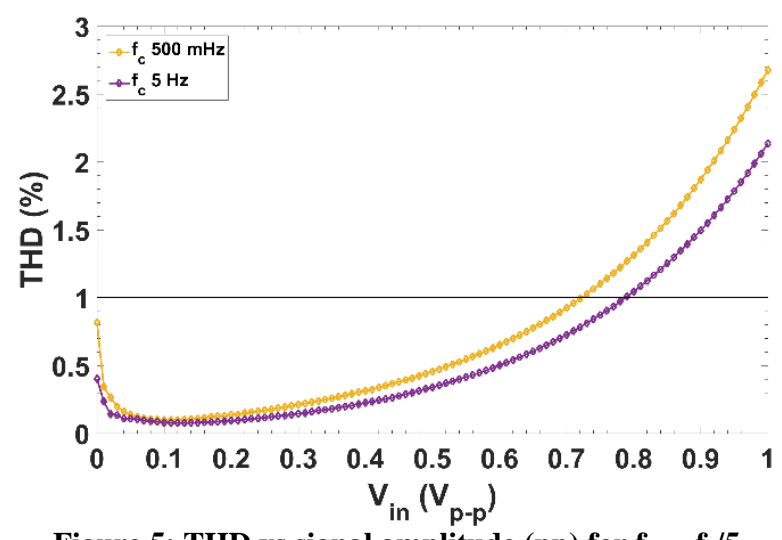

Figure 5: THD vs signal amplitude (pp) for $f_{\text {in }}=f_{c} / 5$.

Table 1. LPF performance comparison with similar works.

\begin{tabular}{|c|c|c|c|c|}
\hline Parameter & This work & $2004[1]$ & $2007[3]$ & $2011[4]$ \\
\hline Tech. $(\mu \mathrm{m})$ & 0.18 & 0.8 & 0.35 & 0.35 \\
\hline $\mathrm{V}_{\text {supply }}(\mathrm{V})$ & 1.8 & \pm 1.5 & 3.3 & 1 \\
\hline $\mathrm{I}_{\text {Total }}(\mu \mathrm{A})$ & 1.5 & $0.077+2.17$ & $50-500$ & 0.005 \\
\hline Power $(\mu \mathrm{W})$ & 2.7 & $0.23+6.5^{(\mathbf{b})}$ & $<1650$ & 0.005 \\
\hline $\mathrm{C}_{\text {Total }}(\mathrm{pF}) /$ pole & 50 & 70 & 52.5 & 40 \\
\hline Offset & $1 \%$ & NA & NA & NA \\
\hline $\mathrm{T}$ range $\left({ }^{\circ} \mathrm{C}\right)$ & $-40-120$ & NA & $0-80$ & NA \\
\hline ICMR (V) & $0.35-1.6$ & NA-Not Available & $0.85-2.85$ & $0.4-0.55$ \\
\hline $\mathrm{f}_{\mathrm{c}}(\mathrm{Hz})$ & $0.114-2.5 \mathrm{k}$ & $0.1-5$ & $1.5-15$ & $0.002-90$ \\
\hline Noise $\left(\mu V_{\text {rms }}\right)$ & $11.3 ; 12.8^{(\mathrm{a})}$ & NA & NA & $32 @ \mathrm{f}_{\mathrm{c}}=1 \mathrm{~Hz}$ \\
\hline THD@1\%( $\left(\mathrm{V}_{\mathrm{pp}}\right)$ & $0.72 ; 0.79^{(\mathrm{a})}\left(\mathrm{f}_{\mathrm{in}}=\mathrm{f}_{\mathrm{c}} / 5\right)$ & NA & $1 @ \mathrm{f}_{\mathrm{c}}=1 \mathrm{~Hz}, \mathrm{f}_{\mathrm{in}}=\mathrm{f}_{\mathrm{c}} / 5$ & $0.14 @ \mathrm{f}_{\mathrm{c}}=\mathrm{f}_{\mathrm{in}}=1 \mathrm{~Hz}$ \\
\hline Order & 1 & 1 & 2 & 1 \\
\hline Area $\left(\mathrm{mm}^{2}\right)$ & 0.051 & 0.1 core & 0.336 & 0.07 \\
\hline Dyn.range (dB) & $>80$ & NA & $>60$ & 64 \\
\hline
\end{tabular}

$$
{ }^{(a)} f_{c}=0.5 ; 5 \mathrm{~Hz} ;{ }^{(b)} 0.23 \mu \mathrm{A} \text { core }+6.5 \text { bias circuitry }
$$

Revista "Jornada de Jóvenes Investigadores del I3A", vol. 6 (Actas de la VII Jornada de Jóvenes Investigadores del I3A - 8 de junio de 2018). ISSN 2341-4790. 